\title{
Correction \\ Correction: Peponi, A.; Morgado, P. Transition to Smart and Regenerative Urban Places (SRUP): Contributions to a New Conceptual Framework. Land 2021, 10, 2
}

\author{
Angeliki Peponi ${ }^{1,2, *(D)}$ and Paulo Morgado ${ }^{2}$ (D) \\ 1 Faculty of Environmental Sciences, Czech University of Life Sciences Prague, \\ 16500 Praha-Suchdol, Czech Republic \\ 2 Centre of Geographical Studies, Institute of Geography and Spatial Planning, Universidade de Lisboa, \\ 1600-276 Lisboa, Portugal; paulo@campus.ul.pt \\ * Correspondence: a.peponi@campus.ul.pt
}

check for updates

Citation: Peponi, A.; Morgado, P. Correction: Peponi, A.; Morgado, P. Transition to Smart and Regenerative Urban Places (SRUP): Contributions to a New Conceptual Framework. Land 2021, 10, 2. Land 2022, 11, 318. https://doi.org/10.3390/ land11030318

Received: 18 January 2022 Accepted: 18 January 2022

Published: 22 February 2022

Publisher's Note: MDPI stays neutral with regard to jurisdictional claims in published maps and institutional affiliations.

Copyright: (C) 2022 by the authors. Licensee MDPI, Basel, Switzerland. This article is an open access article distributed under the terms and conditions of the Creative Commons Attribution (CC BY) license (https:// creativecommons.org/licenses/by/ $4.0 /$ )

\section{Error in Figure/Table Caption}

In the original publication [1], there was a mistake in the caption of Figure 2 as published: Conceptualizations of sustainable development [37]. The corrected "Conceptualizations of sustainable development [38]." appears below. The authors apologize for any inconvenience caused and state that the scientific conclusions are unaffected. The original publication has also been updated.

Text Correction

There was an error in the original publication.

A correction has been made to 1 . Introduction, paragraph 2:

"Batty" will be changed into "Batty (2018)"

Text Correction

There was an error in the original publication.

A correction has been made to 1 . Introduction, paragraph 2:

"Tuan" will be changed into "Tuan (1977)"

Text Correction

There was an error in the original publication.

A correction has been made to 1 . Introduction, paragraph 2:

"Mang and Reed" will be changed into "Mang and Reed (2012)"

Text Correction

There was an error in the original publication.

A correction has been made to 1 . Introduction, paragraph 6:

"Peponi and Morgado" will be changed into "Peponi and Morgado (2020)"

Text Correction

There was an error in the original publication.

A correction has been made to 2. Conceptualizing a Smart-Regenerative Framework for Urban Complex Places, paragraph 1:

"Peponi and Morgado" will be changed into "Peponi and Morgado (2020)"

Text Correction

There was an error in the original publication.

A correction has been made to 2. Conceptualizing a Smart-Regenerative Framework for Urban Complex Places, 2.1. Urban Places as Metabolic Complex Systems, paragraph 4:

"Newell and Cousins" will be changed into "Newell and Cousins (2015)" 


\section{Text Correction}

There was an error in the original publication.

A correction has been made to 2 . Conceptualizing a Smart-Regenerative Framework for Urban Complex Places, 2.1. Urban Places as Metabolic Complex Systems, paragraph 5:

"Wachsmuth" will be changed into "Wachsmuth (2012)"

\section{Text Correction}

There was an error in the original publication.

A correction has been made to 2. Conceptualizing a Smart-Regenerative Framework for Urban Complex Places, 2.2. Urban Places as Smart Complex Systems, paragraph 3:

"Ahvenniemi et al." will be changed into "Ahvenniemi et al. (2017)"

\section{Text Correction}

There was an error in the original publication.

A correction has been made to 2. Conceptualizing a Smart-Regenerative Framework for Urban Complex Places, 2.2. Urban Places as Smart Complex Systems, paragraph 3:

"Harrison et al." will be changed into "Harrison et al. (2010)"

\section{Text Correction}

There was an error in the original publication.

A correction has been made to 2. Conceptualizing a Smart-Regenerative Framework for Urban Complex Places, 2.2. Urban Places as Smart Complex Systems, paragraph 3:

"Caragliou et al." will be changed into "Caragliou et al. (2011)"

\section{Text Correction}

There was an error in the original publication.

A correction has been made to 2. Conceptualizing a Smart-Regenerative Framework for Urban Complex Places, 2.2. Urban Places as Smart Complex Systems, paragraph 3:

"Angelidou" will be changed into "Angelidou (2014)"

\section{Text Correction}

There was an error in the original publication.

A correction has been made to 2. Conceptualizing a Smart-Regenerative Framework for Urban Complex Places, 2.2. Urban Places as Smart Complex Systems, paragraph 3:

"Zanella et al." will be changed into "Zanella et al. (2014)"

\section{Text Correction}

There was an error in the original publication.

A correction has been made to 2. Conceptualizing a Smart-Regenerative Framework for Urban Complex Places, 2.2. Urban Places as Smart Complex Systems, paragraph 4:

"Peponi and Morgado" will be changed into "Peponi and Morgado (2020)"

\section{Text Correction}

There was an error in the original publication.

A correction has been made to 2. Conceptualizing a Smart-Regenerative Framework for Urban Complex Places, 2.3. Urban Places as Regenerative Complex Systems, paragraph 2:

"Lyle" will be changed into "Lyle (1996)"

\section{Text Correction}

There was an error in the original publication.

A correction has been made to 2. Conceptualizing a Smart-Regenerative Framework for Urban Complex Places, 2.3. Urban Places as Regenerative Complex Systems, paragraph 3:

"Geisendorf and Pietrulla" will be changed into "Geisendorf and Pietrulla (2018)" 


\section{Text Correction}

There was an error in the original publication.

A correction has been made to 2. Conceptualizing a Smart-Regenerative Framework for Urban Complex Places, 2.3. Urban Places as Regenerative Complex Systems, paragraph 3:

"Faraud" will be changed into "Faraud (2017)"

\section{Text Correction}

There was an error in the original publication.

A correction has been made to 2. Conceptualizing a Smart-Regenerative Framework for Urban Complex Places, 2.3. Urban Places as Regenerative Complex Systems, paragraph 3:

"Naboni et al." will be changed into "Naboni et al. (2019)"

\section{Text Correction}

There was an error in the original publication.

A correction has been made to 3. Smart and Regenerative Urban Places (SRUP): A New Conceptual Framework, paragraph 4:

"Zari et al." will be changed into "Zari (2012)"

\section{Text Correction}

There was an error in the original publication.

A correction has been made to 3. Smart and Regenerative Urban Places (SRUP): A New Conceptual Framework, paragraph 10:

"Sepe" will be changed into "Sepe (2014)"

\section{Text Correction}

There was an error in the original publication.

A correction has been made to 4. Smart and Regenerative Urban Places: Main Challenges and Discussion, paragraph 2:

"Zari" will be changed into "Zari (2012)"

\section{Text Correction}

There was an error in the original publication.

A correction has been made to 4. Smart and Regenerative Urban Places: Main Challenges and Discussion, paragraph 5:

"Callaud and Laperche" will be changed into "Callaud and Laperche (2016)"

The authors apologize for any inconvenience caused and state that the scientific conclusions are unaffected. The original publication has also been updated.

\section{Reference}

1. Peponi, A.; Morgado, P. Transition to Smart and Regenerative Urban Places (SRUP): Contributions to a New Conceptual Framework. Land 2021, 10, 2. [CrossRef] 